\title{
Thinking to circularity in temporary textile architecture: end of life and reuse and re-manufacturing scenarios
}

\author{
C. Monticelli*, S. Viscuso*, A. Zanelli* \\ * Polythecnic of Milan, Dept. Architetture, Built Enviroment and Construction Engineering \\ Via G. Ponzio, n.33, Milan, - Italy \\ e-mail: carol.monticelli, salvatore.viscuso@polimi.it, alessandra.zanelli@polimi.it, web page: \\ http://www.textilearchitecture.polimi.it
}

\begin{abstract}
Designing for longevity ensures the long-term durability, utilisation and value of assets. Durable materials and robust construction standards can reduce maintenance costs and extend the economic viability of a building or structure ${ }^{1}$. Thinking to circularity in the built environment means to ensure maximum end-of-life material reuse or recycling by separation of components, especially if the life span is short, as happened for the textile temporary architectures. The use of repurposed materials, components and structures supports their circulation within the industry and minimises the need for virgin materials. And when the issue of waste is examined as a result of architectural design, it is possible to establish where and how the architect can contribute to the solution of these challenges.

The paper objectives are, at first, to propose a comprehensive picture of design strategies to be adopted prior to the construction of temporary textile architecture, along with the processes endured at the end of the life cycle, aiming to reduce the environmental impacts. Secondary, a potential classification of the membrane materials and short life span projects ${ }^{2}$ is established to evaluate the state of the art in terms of end of life scenarios and possible virtuous remanufacturing approaches. Finally, a deepen comparison regarding the existing Environmental Products Declarations of textiles membranes for architectures is carried out in order to understand the available information for the design choices from the designers point of view.

By the proposed analysis the outcomes underline how the reasons for the limited diffusion of recycling procedures and even the lack of running plants mainly stand by their costs. Users are often unaware of the economic advantages of reuse and recycle, given that the savings are too delayed in time to be properly assessed. Nevertheless, this value is more appreciated when it comes to projects of greater impacts.
\end{abstract}

Keywords: end-of-life, temporary textile architecture, EPDs, re-manufacturing, reuse.

\footnotetext{
1 12. Ellen MacArthur Foundation, CE100 (2016), Circularity in the built environment: case studies. Available at https://www.ellenmacarthurfoundation.org/assets/downloads/ Built-Env-Co.Project.pdf

16. European Commission (2015), Closing the loop - An EU action plan for the Circular Economy. COM 614.

2 Modern Teahouse, Kengo Kuma, Frankfurt (2010), Aquatics Center, Zaha Hadid Architects, London (2012); Basketball Arena, Wilkinson Eyre, London (2012); Luna Rossa Team Base, RPBW, Valencia (2006).
} 